\title{
SOBRE A INDUMENTÁRIA NA FESTA POPULAR IMAGENS, SIGNOS E FANTASIAS
}

Regina Moura

A indumentária como produto da cultura popular brasileira e até certo ponto mediadora de signos e representações, imagens e imaginário do contexto em que está inserida. Considera-se que na festa popular os trajes expressam linguagem simbólica que transcende o valor funcional da roupa, sobretudo quando propõem a construção de personagens, sinalizam valores culturais ou relações com o corpo pela ornamentação, fantasia e teatralização. Para tanto, analisa algumas indumentárias de folguedos populares, em especial do bumba meu boi, em suas possibilidades de linguagem plástica, estética e simbólica. [Abstract on page 245]

INDUMENTÁRIA, BUMBA MEU BOI, FESTA POPULAR, CULTURA BRASILEIRA. 
A proposta deste trabalho é refletir sobre a indumentária no contexto da festa popular, considerando-se que nesse espaço de trocas simbólicas ela sinalizaria diversas questões através de imagens-vestimentas, máscaras e performances.

Um olhar sobre essa produção indumentária nos remete a seu valor enquanto produto cultural, símbolo estético da cultura em que está inserida, podendo, nesse sentido, configurar relações com o corpo tais como ornamentação, fantasia e teatralização, além de expressar linguagem simbólica que transcende seu valor funcional, uma vez que propõe a reinvenção do sujeito pela construção do personagem.

Nos espetáculos dramáticos populares, em que o cenário é rudimentar ou apenas insinuado, a carga estética e simbólica se concentra na indumentária (adereços, figurinos), basicamente o suporte visual do drama, dos personagens e dessa construção como um todo. Nesse viés, a vestimenta funciona como aparato estético construído na intenção de constituir uma segunda pele, investida de complexo sistema de signos e linguagens plásticas.

A partir dessas questões analisa-se o sentido da indumentária na festa popular brasileira, em especial no folguedo bumba meu boi, indagando seu valor enquanto signo, objeto estético ou produto artístico, aqui atravessado por simbolismo e visualidade próprios da manifestação dramática.

Conforme Geertz, os elementos simbólicos ou sinais registrados nas diferentes culturas possuem valor de linguagem, compõem sistemas semióticos - estéticos - próprios da cultura em que se apresentam. Desse modo, o sentido de uma obra de arte é variável de indivíduo para indivíduo e de sociedade para sociedade porque "a participa-

1 Sobre a transformação de ritos cristãos em teatro, Tinhorão comenta que "no Brasil, esse deslocamento da teatralização ritual dos episódios da história sagrada, das igrejas para as ruas, podia ser comprovado já no primeiro século de colonização (...), proporcionado pela verdadeira encenação popular em que se transformara a procissão dos Passos (...) que se condensou teatralmente numa espécie de auto dramático ambulante" (TINHORÃO, 2000: 68). ção no sistema particular que chamamos de arte só se torna possível através da participação no sistema geral de formas simbólicas que chamamos de cultura" (GEERTZ, 1998: 165). Assim também, no caso do objeto de arte-indumentária gerado pela cultura brasileira é preciso avaliá-lo à luz do saber local, na materialização dos traços culturais, pelos saberes do povo e seu imaginário.

Vale considerar que nosso imaginário popular guarda memórias do modelo sociocultural ibérico medieval, gradativamente enriquecidas pelas contribuições árabes e aquelas geradas pela miscigenação indígena e africana, todo esse processo acrescido do papel da religião. Segundo Suassuna existe uma força imanente à cultura popular brasileira que a torna resistente, um universo simbólico feito pelo povo e que se inscreve tanto no conjunto dos espetáculos, como no caso do bumba meu boi, quanto nos versos do romanceiro, na literatura oral, nas xilogravuras das capas dos folhetins, nos ornamentos e nas bandeiras, e em tudo aquilo que o povo cria para viver ou se deleitar (SUASSUNA ET AL., 1986: 183). 
No Brasil, a religiosidade ritualizada em procissões e cortejos, herança medieval do cristianismo ocidental, transformou-se mediante longo processo social e cultural em espetáculos dramáticos populares. Já no século XVI o povo se inseria nas cerimônias religiosas no pátio das igrejas, onde se dramatizavam episódios da história sagrada, que se popularizavam acrescentados de valores lúdicos. Nessas festas transparecem conteúdos significativos de miscigenação de elementos do teatro medieval, ${ }^{1}$ por sua vez originário do rito religioso da missa cristã - os mistérios - cujos participantes se transformavam em personagens sagrados por meio das indumentárias, mediadoras de signos e visualidades.

Em meio à complexidade cultural própria do Brasil, esse tipo de espetáculo conservou-se em festas populares de caráter dramático, ou seja, nas representações envolvidas por aspectos do saber popular e da tradição, em que interagiram diferentes valores étnicos, culturais e estéticos. Dramas sacros ${ }^{2}$ construídos na mistura de sagrado, profano, lúdico e carnavalesco que culminaram em espetáculos populares como congadas, cheganças, reisados, cavalhadas, folia de reis, carnaval e bumba meu boi.

Cada espetáculo popular apresenta formas particulares de arte e dramaturgia coerentes com o estrato cultural e social brasileiros, expressando estética dionisíaca - relativa aos atributos de Dioniso $^{3}$ - inserida em formas, cores e gestuais capazes de delimitar determinada identidade visual. Michel Maffesoli observa que a festa em si carrega aspectos dionisíacos e, já em suas origens, "aliava práticas orgíacas aos cultos à natureza (...), festa da primavera era também religião da natureza - é nesse contexto que se pode entender o dionisíaco, tal como uma fantasia" (MAFFESOLI, 1985: 74).

Por outro lado, a festa interrompe momentaneamente as regras sociais, desconstruindo a ordem vigente; nessa brecha de tempo "tudo pode acontecer, porque tudo é possível, incluindo-se aí o apagamento dos papéis impostos pela cultura e pela sociedade" (DUVIGNAUD, 1977: 45). Isso significa que a festa instaura outras formas de relacionamento e mesmo de valores estéticos: "o momento da festa (...) permite que os atores, as ações e os objetos apresentem-se com uma carga máxima de significados, destacandose cada gesto, cada palavra, cada peça de indumentária, cada ato ritual com uma intensa carga simbólica (FERREIRA, 2005: 312).

2 De acordo com Bakhtin (1987: 4), "quase todas as festas religiosas possuíam um aspecto cômico popular e público, consagrado também pela tradição, nenhuma festa se realizava sem a intervenção dos elementos de uma organização cômica, (...) para rir no período da festividade".

3 Dioniso tem, entre outros atributos, a característica de ser o deus da vida, da metamorfose, da desmedida, do êxtase $e$ da música, em contraponto a Apolo, aquele que confere forma, expressa exatidão, harmonia e prudência. Em termos gerais, podemos chamar dionisíaco e apolíneo a tudo o que se relaciona com os mitos gregos de Apolo e Dioniso. A esse repeito consultar Brandão (1991), Chevalier e Gheerbrant (1996) e Maffesoli (1985). Nietszche em O nascimento da tragédia (1992) trata a questão do apolíneo e dionisíaco para explicar a origem da tragédia

No âmbito da cultura popular brasileira, o bumba meu boi desencadeia um processo festivo singular, dionisíaco, carnavalizado (que inclui o lúdico, o cômico, a pantomina, acrobacias e o improviso) ao lado da questão da morte e ressurreição (possivelmente reminiscente de antigos rituais de fertilização), aspectos emoldurados pela indumentária em sua possibilidade de signo e fantasia. 


\section{INDUMENTÁRIA: SIGNOS E VISUALIDADES}

4 o folguedo popular bumba meu boi surgiu no século XVIII, como forma de crítica à situação social dos negros e índios, podendo variar de nome conforme a região (boibumbá ou boi de Parintins, no Amazonas; bumba meu boi, no Nordeste; boi de mamão, em Santa Catarina; boizinho, no Rio Grande do Sul, entre outros), popularizando-se no Maranhão onde ocorre no mês de junho em homenagem a São João. Esse auto dramatiza a história de um rico fazendeiro dono de um boi muito bonito, que é roubado por Pai Chico, para satisfazer sua mulher, Catarina, que, grávida, tem desejo de comer a língua do boi. o fazendeiro manda procurar o boi e o encontra doente. Os pajés curam o animal e descobrem a real intenção de Pai Chico, no final perdoado pelo fazendeiro, que celebra a saúde do boi com uma grande festa.

5 Considerando a relação da commedia dell'arte com o teatro popular, suas apresentações são originárias das farsas representadas pelos bobos da corte, pelas ruas e praças públicas, sempre caracterizadas pela improvisação e capacidade gestual dos artistas; esse modelo de teatro surgiu na
Pode-se dizer que a indumentária é um dos elementos fundamentais da festa popular e que colabora profundamente para a visualidade do espetáculo, como objeto cênico emblemático capaz de compor e materializar personagens. Certamente em sua conotação cênica vai além do sentido do vestir (proteger, ornamentar, cobrir), libertando-se do real e do decorativo na intenção de um referencial estético-simbólico. A indumentária "deve portanto contribuir para a representação, ajudando ao mesmo tempo a caracterização do personagem e a expressividade do corpo" (ROUBINE, 1998: 148).

Artaud traduz a indumentária-figurino em objeto imantado, uma vestimenta cerimonial - signo sagrado -, cujos poderes mágicos o ator deveria multiplicar. Nessa perspectiva coloca o teatro e a indumentária cênica no patamar do mágico "pelas formas e por tudo que for gesto, ruído, cor, plasticidade (...) devolvê-la a sua destinação primitiva é recolocá-la em seu aspecto religioso e metafísico" (ARTAUD, 1999: 77), como se a indumentária possuísse "aura" ou dela emanasse uma carga simbólica e mitológica.

Sendo assim, é importante observar, na análise da indumentária, o diálogo corpo-vestimenta e seus códigos, considerando que roupa é imagem, signo, linguagem, posto que o vestuário fala - "tal como a linguagem verbal a vestimenta serve para transmitir certas formas significativas (...) identificar posições ideológicas segundo significados transmitidos e formas significativas que foram escolhidas para os transmitir" (ECO, 1989: 17) -, podendo caracterizar e identificar grupos, etnias, tribos, assim como os diferentes personagens cênicos.

As indumentárias dos espetáculos populares dramáticos no Brasil apresentam em geral rica linguagem visual atravessada por aspectos da miscigenação estético-cultural, própria de nossa cultura, reinterpretada e recriada nas roupas e máscaras, nos detalhes e ornamentos. No caso do bumba meu boi, as roupas são acrescidas de possibilidades plásticas, estéticas e simbólicas, configurando um figurino-cenário-corpo performático que pontua as cenas no espaço público. Até que ponto a eficácia ritual da indumentária vai pontuar essa encenação atravessada pela vivência do sagrado e do profano, da arte, do rito e riso?

Sem dúvida, o espetáculo do bumba meu boi ${ }^{4}$ apresenta narrativa própria que o distingue e caracteriza, sobretudo nos trajes atravessados por nítidas influências da commedia dell'arte ${ }^{5}$ e mesmo 
da estética medieval. Marlyse Meyer (1993) estabelece aproximações entre o bumba meu boi e a commedia dell'arte, por intermédio dos mascarados Mateus, Birico e Catirina, que apresentam fortes semelhanças com os zannis ${ }^{6}$ da commedia: "o boi é tão rico quanto a commedia dell'arte, gênero com o qual foi aproximado e com o qual se parece (...) os comediantes ambulantes, um jogo cênico que ridiculariza a miséria, por meio de máscaras, trejeitos corporais (...) roupas remendadas (MEYER, 1993: 37). Ariano Suassuna (2008:11), por sua vez, visualiza representações de uma estética medieval nos atores do bumba meu boi "vestidos de espelhos, com as cabeças ornamentadas com chapéus que parecem templos do Sião ou mitras episcopais; os trajes litúrgicos da Igreja e dos militares; a roupa solene e cômica do doutor".

\section{O BUMBA MEU BOI: REPRESENTAÇÕES E FANTASIAS}

O bumba meu boi, de acordo com Mário de Andrade, é dança dramática,7 derivada do tema "mítico" da morte e da ressurreição do boi (ANDRADE, 1982: 23), mas que em seu contexto histórico, como já observado, mantém a religiosidade numa mistura de sagrado e profano, impregnada pela memória das culturas ibérica e moura, por elementos da commedia dell'arte e pelas tradições étnicas, folclóricas e artesanais que compõem parte do imaginário popular brasileiro. Câmara Cascudo nele observa, em termos estéticos e sociais, uma forma de afirmação popular ou válvula de escape, que satiriza a sociedade e as autoridades (CASCUDO, 1972).

Nota-se então um incrível senso de espaço cênico, de mímicas, danças e jogos construídos com roupagens e máscaras, ou seja, a estrutura do bumba meu boi ${ }^{8}$ condensa um enredo desenvolvido de forma dramática e coreográfica em torno do tema central da morte e ressurreição do boi, esta última, ponto alto da festa, em que ocorre a dança do boi. A cena é composta por vários personagens tipos populares burlescos, animais e figuras míticas, que provavelmente evoluíram das antigas farsas europeias, o que faz supor sua forma de representação, por meio do improviso, da pantomina e de acrobacias.

O espetáculo em si aglutina teatro, dança, canto, música, comicidade, burlesco, medo, riso, tudo amarrado pelos personagens Pai Chico, Mãe Catirina, boi, patrão, vaqueiros, índios, índias, caboclos (caboclo real, caboclo de pena) e cazumbás, com suas indumentárias coloridas, especialmente as do boi, do caboclo de fita, do caboclo de pena e do cazumbá por sua riqueza de signos e elementos estéticos.
Itália no século XV (se estendeu à França até o século XVIII), inaugurou um estilo e nova linguagem, caracterizada pelo aspecto cômico.

6 Zannis eram tipos populares da commedia dell'arte e dividiam-se em duas categorias: a do esperto e fomentador de intrigas, e a do rude e simplório, com suas brincadeiras atrapalhadas $e$ comicidade. Sobre a commedia dell'crte ver Freitas, 2008.

7 Mário de Andrade, ao observara importância do boi na vida brasileira, faz analogia ao chefe no organismo tribal e ao mouro na conquista de terras, desse modo atribuindo ao boi, ao chefe e ao mouro valor místico, religioso $e$ sempre simbólico.

8 É importante observar que a figura mítica do boi é encontrada em antigos rituais totêmicos de diferentes culturas. Sobre 0 simbolismo e os mitos relativos a esse assunto, ver Chevalier e Gheerbrant, 1996. 
Do ponto de vista da encenação, destaca-se o boi. O couro do boi, como é chamada a indumentária do tripa - o brincante que faz dançar o boi -, pode ser comparado a uma máscara de corpo inteiro, confeccionada em veludo com aplicação de bordados e ajustada a uma armação de madeira.

Os bordados seguem a tradição artesanal, ricamente elaborados com canutilhos, miçangas, lantejoulas e contas, e sua linguagem plástica detalha paisagens, cenas históricas e santos com riqueza de detalhes. Essas imagens, sagradas - figuras de santos, pas-

9 A chita-tecido de algodão, pano popular - carrega conotação de "popular brasileiro", fazendo parte de diversas celebrações como bumba meu boi, maracatu, festa do Divino, carnaval; conforme Cardia "a chita é uma fotografia de nossa cultura e deveria ser tombada porque está em extinção", ver Kubrusly, Mellão, Imbroisi (2005).

10 Observar a possível analogia entre o cazumbá e outros personagens populares como o clóvis da festa carnavalesca, o palhaço da folia de reis, os mascarados de Pirenópolis, identificados por seu aspecto cômico, astuto, travesso e pelo uso de máscaras. A indumentária-fantasia desses brincantes confere um ar matreiro e perigoso e ao mesmo tempo autoriza posturas irreverentes. sagens bíblicas - ou profanas - o brasão do Maranhão, a bandeira do Brasil - podem apresentar ornamentação de flores em torno do bordado central.

De qualquer modo as indumentárias representativas dessa dança dramática expressam nítida mistura étnica, incluindo elementos medievais, orientais, africanos e indígenas, o que se ilustra, por exemplo, pelo uso de tecidos como o veludo e a chita ${ }^{9}$ ou, no caso do caboclo de fita, pela roupagem supercolorida, que reúne múltiplos elementos e enfeites, emoldurada por grandes chapéus rodeados de fitas coloridas.

Os índios, o caboclo real e o caboclo de pena, se destacam na encenação pelo efeito visual que integra a estética das roupas com a coreografia que realizam.

Destaca-se também o cazumbá, ${ }^{10}$ tanto pela performance quanto pela roupa e pela máscara, fundamentais no contexto do ritual. Personagem híbrido, misterioso e cercado de magia - relaciona-se, aliás, o termo cazumbá a duende, espírito ou fantasma -, sua função na festa, além de divertir os participantes, é deslocar-se à frente do grupo no início da brincadeira e atuar no ritual de morte do boi, que encerra a festa.

Seu figurino é basicamente composto pela máscara colorida, com formas animalescas variadas, e túnica decorada com estrelas, bichos, figuras de santos, alegorias, inscrições e imagens, e armada por um cofo de palha na altura dos quadris. Em geral esse brincante traz em uma das mãos um sino e na outra chocalho (para marcar o ritmo) ou chicote (para espantar o público), ou bonecas, facas de brinquedo e outros objetos que possam caracterizar clima assustador e atribuir aspecto travesso ao personagem.

O ponto central dessa indumentária é a máscara ou careta, que concede ao cazumbá a dimensão simbólica necessária à encenação. As máscaras, geralmente bem coloridas e adornadas com diferentes elementos e bordados, podem ser classificadas em três tipos: focinho (de madeira pintada, em formato de animais ou monstos); cabeleira (de cerdas de cavalo, pelo de carneiro e tecidos tinturados em cores fortes, geralmente 
são bordadas e possuem orifícios para olhos, nariz e boca); e torre (verdadeiras esculturas construídas em madeira e isopor, muito decoradas, às vezes com iluminação a pilha).

Possivelmente especulação mais profunda sobre o bumba meu boi relacionasse aspectos do cazumbá a signos da cultura africana, como, por exemplo, características da indumentária ancestral do Daomé com seus guizos, chocalhos e máscaras, do mesmo modo que outras indumentárias, como o couro do boi (formas, cores, bordados, ornamentos), podem estar associadas a antigas tradições europeias.

Diante do bumba meu boi nos deparamos com um elenco de signos e representações, personagens e indumentárias que de certa forma preservam e ritualizam nossa memória cultural, revivida ciclicamente em cada festejo. É possível que essas formas-indumentárias carreguem traços de nosso imaginário e, enquanto elementos de ritualização, contenham um pouco de nossas histórias, em meio a rica linguagem simbólica, plástica e estética, teatralizando nossa identidade cultural.

\section{REFERÊNCIAS BIBLIOGRÁFICAS}

ANDRADE, Mário. Danças dramáticas. Belo Horizonte: Itatiaia, 1982.

ARTAUD, Antonin. O teatro e seu duplo. São Paulo: Martins Fontes, 1999.

BAKHTIN, Mikhael. A cultura popular na Idade Média e no Renascimento. São Paulo: Hucitec, 1987.

BERTHOLD, Margot. História mundial do teatro. São Paulo: Perspectiva, 2000.

BOUCHER, François. Histoire du costume en Occident. Paris: Flammarion, 1983.

BURKE, P. Cultura popular na Idade Moderna. São Paulo: Companhia das Letras, 1989.

BRANDÃO, Junito de Souza. Mitologia grega. Petrópolis: Vozes, 1991.

CASCUDO, Câmara. Antologia do folclore brasileiro. São Paulo: Martins Fontes, s.d. Dicionário do folclore brasileiro. Rio de Janeiro: Ediouro, 1972.

CAVALCANTI, Maria Laura. Tema e variantes do mito: sobre a morte e a ressurreição do boi. Rio de Janeiro, Mana, v.12, abr. 2006.

CHEVALIER e GHEERBRANT. Dicionário de símbolos. Rio de Janeiro: José Olympio, 1996.

DUVIGNAUD, Jean. Festas e civilizações. Rio de Janeiro: Tempo Brasileiro, 1983.

DURKHEIM, Émile. Les formes élémentaires da la vie réligieuse. Paris: PUF, 1968.

ECO, Umberto. O hábito fala pelo monge, in Psicologia do vestir. Lisboa: Assírio e Alvim, 1989.

FERREIRA, Felipe. Inventando carnavais: o surgimento do carnaval acrioca no século XIX e outras questões carnavalescas. Rio de Janeiro: Editora UFRJ, 2005.

FREITAS, Nanci de. A commedia dell'arte: máscaras, duplicidade e o riso diabólico de arlequim. Textos Escolhidos de Cultura e Arte Populares, Rio de Janeiro. v.5, n.1, p. 6574, 2008.

GEERTZ, Clifford. O saber local. Rio de Janeiro: Vozes, 1998.

KUBRUSLY, MELLÃO e IMBROISI. Que chita bacana. São Paulo: A Casa - Casa Museu do Objeto Brasileiro, 2005.

LURIE, Allison. A linguagem das roupas. Rio de Janeiro: Rocco, 1997.

MAFFESOLI, Michel. A sombra de Dionísio. Rio de Janeiro: Graal, 1985. 
MEYER, Merlyse. Caminhos do imaginário no Brasil. São Paulo: Edusp,1993.

NIETZSCHE, F . O nascimento da tragédia. São Paulo: Companhia das Letras, 1992.

PERES, Eraldo. O encantador, Seu Teodoro do boi. Brasilia: Senac, 2007.

ROUBINE, Jean-Jacques. Linguagem da encenação teatral. Rio de Janeiro: Zahar, 1998.

SUASSUNA, Ariano. A compadecida e o romanceiro nordestino. In: at all. Literatura popular em verso. Rio de Janeiro: Casa de Rui Barbosa, 1986. . Auto da compadecida. Rio de Janeiro: Agir, 2008.

STANISLAVSKI, Constantin. A construção do personagem. Rio de Janeiro: Civilização Brasileira, 1996.

TINHORÃO, José Ramos. As festas no Brasil colonial. São Paulo: Editora 34, 2000.

Regina Moura é mestre em antropologia da arte pelo Programa de Pós-Graduação em Artes Visuais/EBA/UFRJ. 